\title{
TECNOLOGIAS DE TRADUÇÃO AUTOMÁTICA: EFEITOS NA COMUNICAÇÃO ACADÊMICA ${ }^{1}$
}

O objetivo do livro de Lynne Bowker e Jairo Buitrago Ciro (2019), pesquisadores da Universidade de Ottawa, Canadá, é discutir como a tradução automática é empregada no contexto da comunicação acadêmica (scholarly communication) e esclarecer de que maneira essa tecnologia pode ser utilizada de forma mais eficaz.

De acordo com Bowker e Buitrago Ciro, o livro Machine Translation and Global Research (Tradução Automática e a Pesquisa Global) pode ser do interesse de diferentes públicos, tais como:

- Agentes de serviços linguísticos (literacy brokers) ou mediadores textuais, que, além dos autores, podem realizar todos os diferentes tipos de intervenção direta ou indireta na produção de textos. Os agentes de serviços linguísticos incluem tradutores, editoras, editores de periódicos científicos e bibliotecários, que dão apoio aos autores durante suas tarefas de escrita acadêmica; alguns desses agentes podem ajudar os autores a adquirirem conhecimentos básicos sobre tradução automática;

- Pesquisadores que têm o inglês como língua adicional e que querem usar adequadamente a tradução automática para prover a disseminação eficaz de seus resultados de pesquisa para uma comunidade científica mais ampla; e/ou

- Pesquisadores nativos de língua inglesa, que podem divulgar seus resultados de pesquisa em sua própria língua. Esses pesquisadores necessitam estar cientes de como a tradução automática afeta seus textos e como podem facilitar a comunicação especializada com outros pesquisadores.

Para Bowker e Buitrago Ciro, ao desenvolverem seus conhecimentos sobre a tradução automática, ou seja, ao adquirirem uma compreensão mais aprofundada de como trabalhar eficazmente com esse tipo de ferramenta, os agentes de serviços linguísticos e os pesquisadores estarão mais aptos a realizarem os processos que envolvem a comunicação acadêmica e a assegurarem a máxima participação de pesquisadores de todo o mundo, especialmente considerando os impactos globais do inglês como a língua da ciência.

\footnotetext{
Universidade Federal de Uberlândia (UFU). Uberlândia - MG - Brasil. marileide.esqueda@ufu.br. ORCID: 0000-0002-6941-7926.

1 BOWKER, Lynne; BUITRAGO CIRO, Jairo. Machine translation and global research: towards improved machine translation literacy in the scholarly community. United Kingdom: Emerald Publishing Limited, 2019. 127 p. ISBN: 978-1-78756-722-1 / doi: 10.1108/978-1-78756-721-420191002.
} 
O livro está escrito em inglês e é composto por uma introdução, cinco capítulos, uma seção final de 12 linhas e 140 referências, dentre as quais cinco delas são dos próprios autores, atestando suas experiências no campo das tecnologias de tradução, incluindo a tradução automática. O livro baseia-se nos trabalhos anteriores de Bowker e Buitrago Ciro com textos pragmáticos (usualmente técnicos e científicos) que, utilizados como exemplos, foram parcialmente submetidos a sistemas de tradução automática como o Google Translate, Bing Translator (da Microsoft) e DeepL, e posteriormente analisados pelos autores.

A introdução apresenta uma questão geral: a tradução automática pode ajudar as pessoas, especialmente os pesquisadores, a se comunicarem melhor? A resposta, para Bowker e Buitrago Ciro, não é simples, mas a questão é certamente digna de investigação. De acordo com os autores:

Se queremos as melhores e mais brilhantes mentes do planeta trabalhando juntas para resolver problemas como mudanças climáticas, câncer e crises energéticas, então precisamos ter certeza de que eles podem compartilhar, de forma eficaz, entre si, seus resultados de pesquisa. ${ }^{2}$ (BOWKER; BUITRAGO CIRO, 2019, p.1, tradução nossa).

Também afirmam na Introdução do livro que o inglês emergiu como a língua internacional da comunicação acadêmica - particularmente nos domínios da ciência e da tecnologia - apesar do fato de apenas cerca de $6 \%$ da população mundial falar inglês como língua nativa. Portanto, levantam a questão: "O que isso significa para os restantes 94\% que não têm o inglês como língua nativa?"3 (BOWKER; BUITRAGO CIRO, 2019, p.1, tradução nossa). Na opinião dos autores, isso significa que a comunicação acadêmica precisa de ferramentas e técnicas, e os pesquisadores precisam de treinamento em tradução automática para ajudá-los a se engajarem e contribuírem com a literatura científica em suas áreas, para o bem da sociedade.

O Capítulo 1, intitulado Scholarly Communication (Comunicação Acadêmica), fornece uma visão geral do estado da arte da comunicação acadêmica e da evolução do inglês como língua internacional de disseminação científica. O capítulo se inicia com uma definição de comunicação acadêmica, qual seja, um processo pelo qual cientistas, acadêmicos, estudantes de pós-graduação e outros pesquisadores compartilham e publicam suas descobertas para que elas estejam disponíveis para uma comunidade científica mais ampla e para a sociedade. O capítulo também revela que análises bibliométricas recentes apontam para o crescimento exponencial no desenvolvimento da ciência, levando ao aumento das produções científicas e aos inevitáveis desafios

2 Original: "If we want the best and the brightest minds on the planet working together to solve problems such as climate change, cancer, and energy crises, then we need to make sure that they can effectively share their research findings with one another:" (BOWKER; BUITRAGO CIRO, 2019, p.1).

3 Original: "What does this mean for the other 94\% who do not speak English?" (BOWKER; BUITRAGO CIRO, 2019, p.1). 
linguísticos associados a tal progresso. Bowker e Buitrago Ciro destacam a ascensão do inglês como a língua internacional da comunicação acadêmica, e que a internet também colabora para tal ascensão, uma vez que os sites que lidam com produtos de pesquisa como arquivos no prelo, repositórios institucionais e periódicos on-line são tipicamente disponibilizados em inglês ou, pelo menos, traduzidos e localizados para esse idioma. O capítulo também apresenta uma série de possíveis estratégias disponíveis para pesquisadores que têm o inglês como língua adicional e que desejam publicar os resultados de suas pesquisas nesse idioma.

Machine Translation (Tradução Automática) é o título do Capítulo 2, que oferece aos leitores uma visão mais detalhada do universo da tradução automática, iniciandose com uma breve história de seu surgimento. Partindo de uma epígrafe retirada do trabalho dos autores Hutchins e Somers (1992), que afirmam que a tradução automática é uma das atividades de pesquisa mais desafiadoras, uma vez que envolve a aplicação de conhecimentos teóricos complexos à construção de sistemas, o capítulo introduz as principais abordagens aplicadas às tecnologias de tradução automática. Visto que o objetivo dos autores não é direcionar o conteúdo do capítulo especificamente aos linguistas computacionais, Bowker e Buitrago Ciro evidenciam as vantagens e desvantagens da tradução automática para os usuários em geral. Eles descrevem as limitações das várias abordagens, tais como as abordagens que envolvem métodos baseados em regras (a partir dos quais os pesquisadores tentam programar computadores para processar a linguagem usando regras gramaticais), métodos estatísticos (em que os computadores são treinados a partir de corpora paralelos, para que possam fazer uso substancial de cálculos de probabilidade), abordagens baseadas em corpora (que usam técnicas de combinação de padrões e números), e as recentes abordagens envolvendo redes neurais (sistema de processamento de informação que é inspirado pela forma como os sistemas nervosos biológicos processam a informação, como o cérebro. Esse sistema de tradução automática por redes neurais encontra padrões, tais como pistas contextuais em torno da frase de origem). Independentemente da complexidade dessas abordagens e de seus refinamentos ao longo da história, Bowker e Buitrago Ciro afirmam que a maioria dos desafios enfrentados pelas tecnologias de tradução automática estão relacionados à tarefa de traduzir homonímias e polissemias; ambiguidades nas classes de palavras (ou homografia), ambiguidades estruturais, ordem de substantivos (como na expressão inglesa liquid oxygen tank, em que corre-se o risco de a tradução automática adotar a tradução em português, por exemplo, "tanque líquido de oxigênio" em vez de "tanque de oxigênio líquido", a depender da abordagem do sistema), anáforas, expressões idiomáticas e assim por diante.

Ao introduzir a noção de como se escrever para fins de tradução, isto é, escrever um texto tendo a tradução automática em mente, Bowker e Buitrago Ciro explicam, no Capítulo 3, intitulado Expanding the Reach of Knowledge Through TranslationFriendly Writing (Expandindo o alcance do conhecimento através da escrita amigável à tradução), que se os pesquisadores nativos de língua inglesa reconhecerem como a tradução automática pode ser usada por pesquisadores que têm o inglês como língua 
adicional, eles podem escrever de forma a melhorar a capacidade de tradução de seus resumos e facilitar a compreensão do conteúdo traduzido por essas máquinas. Eles apresentam 10 diretrizes para se escrever textos de forma amigável à tradução automática, com ênfase em resumos de pesquisa, embora reconheçam que a ideia de se escrever em uma linguagem clara e de fácil compreensão não seja nova, tendo surgido na literatura da área de Linguística por meio de conceitos como International English, Standard English, Common English, Global English, Globish, Basic English, Plain English, dentre outros. Eles basearam suas diretrizes em perguntas simples em torno do conceito de "escrita amigável à tradução" (ou pré-edição): 1. para quem os pesquisadores estão escrevendo? 2. Como os leitores podem estar acessando o texto? 3. O que eles querem que esses leitores extraiam do texto? O capítulo também fornece alguns conceitos e definições sobre a pós-edição, que é compreendida pelos autores como o processo de correção de um texto que foi traduzido por um sistema de tradução automática, a fim de corrigir eventuais erros e tornar o texto mais natural. Entretanto, Bowker e Buitrago Ciro alertam que é difícil apresentar diretrizes gerais para a pósedição, pois os erros de tradução automática dependem da combinação de idiomas, tipo de texto, campo temático e sistema e abordagem de tradução automática utilizados.

O Capítulo 4, intitulado Some Wider Implications of Using Machine Translation for Scholarly Communication (Outras implicações sobre o uso da tradução automática para a comunicação acadêmica), afasta-se das especificidades de como os sistemas de tradução automática funcionam para discutir como os usuários podem interagir com eles de forma mais eficaz. O capítulo também enfatiza que a tradução automática online gratuita pode, hoje em dia, ser facilmente acessada por pesquisadores em todo o mundo "com o simples apertar de um botão". Entretanto, o uso dessa tecnologia pode afetar outras pessoas, como os tradutores humanos, por exemplo. Os pesquisadores que optam pelo uso de sistemas de tradução automática têm algumas obrigações éticas para com aqueles cuja produção intelectual é retomada no processo, nem que seja simplesmente reconhecendo o fato de que a tradução automática não elimina a necessidade de tradutores humanos, mas é altamente dependente dela. Bowker e Buitrago Ciro também advertem que os usuários podem imaginar que os dados inseridos em um serviço gratuito de tradução automática on-line simplesmente desaparecem quando o processo de tradução é concluído, mas isso não é verdade. Ao contrário, os fornecedores de serviços de tradução automática estão, em geral, interessados em manter esses dados e possivelmente reutilizá-los no futuro, por exemplo, como dados de treinamento para alimentar os sistemas.

Towards a Framework for Machine Translation Literacy (Em busca da estruturação de um curso de tradução automática) é o título do Capítulo 5, que visa estruturar um curso que desenvolva conhecimentos em tradução automática, que poderia ser usado por agentes de serviços linguísticos, especialmente bibliotecários, para planejar e promover um treinamento eficaz em tradução automática. Eles iniciam o capítulo definindo o termo literacy, que se refere à competência ou ao conhecimento adquirido em uma área específica, apesar de os autores explicarem que é difícil apresentar uma 
definição unívoca de literacy, uma vez que os processos de comunicação acadêmica e tradução automática estão em constante mudança, pois ambas evoluem à medida que o mundo à nossa volta - e a nossa relação com ele - evolui também. Eles propõem um treinamento eficaz em tradução automática na forma de um workshop ou oficina, que poderia ser oferecido pelas universidades e a partir do qual os pesquisadores poderiam:

- adquirir as noções básicas de como os sistemas de tradução automática processam os textos;

- compreender como os sistemas de tradução automática são ou podem ser usados (pelo próprio pesquisador ou por outros pesquisadores) para encontrar, ler e/ou produzir publicações acadêmicas;

- avaliar as implicações associadas ao uso da tradução automática em nível mais amplo;

- avaliar em que consiste uma tradução (automática) amigável de textos acadêmicos;

- criar ou modificar um texto acadêmico para que ele possa ser traduzido mais facilmente por um sistema de tradução automática; e

- modificar o resultado fornecido por um sistema de tradução automática para melhorar a sua precisão e legibilidade.

Bowker e Buitrago Ciro também afirmam que a tradução automática não se constitui como um sistema homogêneo, uma vez que essa tecnologia pode estar baseada em diferentes abordagens (tais como as já citadas abordagens baseadas em regras, estatísticas, baseadas em corpora ou em redes neurais) ou combinarem várias delas. Para os autores, portanto, é provável que ferramentas diferentes produzam traduções diferentes e um único sistema não funcionará igualmente bem para todos os pares de idiomas ou direções. Bowker e Buitrago Ciro destacam que um determinado sistema pode ter um grande volume de dados de treinamento disponíveis para inglês e francês, mas um conjunto consideravelmente menor de dados de treinamento para inglês e islandês, por exemplo, e que os sistemas podem ter um desempenho diferente ao lidarem com textos de diferentes áreas temáticas.

Na conclusão, composta por 12 linhas, os autores concluem que escrever o livro lhes ofereceu uma oportunidade muito satisfatória para ler muitas páginas sobre as pesquisas acadêmicas, sobre a área de comunicação, línguas, formação e tecnologias e para refletir e comparar as suas próprias experiências como pesquisadores e membros da comunidade acadêmica. Nas palavras dos autores, "[...] a produção do livro revelou-se ao mesmo tempo como uma experiência esclarecedora e gratificante que nos levou a novas reflexões sobre a tradução automática e suas aplicações no processo de pesquisa."4 (BOWKER; BUITRAGO, 2019, p.95, tradução nossa).

4 Original: "[...] producing the book has been both an eye-opening and a rewarding experience which has led us to new reflections on machine translation and its applications in the research process." (BOWKER; BUITRAGO, 2019, p.95). 
A meu ver, incluir reflexões e diretrizes sobre a produção de textos visando à comunicação acadêmica, tendo em mente formas de desenvolvimento de conhecimentos básicos sobre tradução automática, é a característica mais importante do livro, já que a história e as abordagens da tradução automática já têm sido amplamente exploradas por muitos outros autores, como destacam Bowker e Buitrago Ciro.

Embora não tenha sido escrito especialmente para professores, alunos de graduação ou pós-graduação em Tradução ${ }^{5}$, o livro de Bowker e Buitrago Ciro inspira cursos universitários inseridos nessa área a otimizarem o ensino da tradução automática na formação de tradutores, especialmente quando os autores discutem os resultados de pesquisas empíricas mostrando que o número de publicações científicas aumentou vertiginosamente desde o fim da Segunda Guerra Mundial. Exploradas pelos autores no Capítulo 2, essas pesquisas também mostram que as traduções profissionais realizadas por tradutores humanos são de alta qualidade, como aquelas realizadas por agências de pesquisas científicas como a Elsevier, Taylor \& Francis, Wiley, American Journal Experts, dentre outras, ao passo que a tradução automática, apesar de seus avanços e novos métodos e abordagens, tem ainda uma qualidade inferior. Nesse sentido, se as publicações científicas crescem, o ensino de tradução automática tem também que emergir como prioridade nos programas de Tradução. Em minha opinião, que se consolidou com a leitura do livro de Bowker e Buitrago Ciro, formar tradutores para utilizarem a tecnologia de tradução automática é um elemento crucial a se considerar, não apenas para que eles façam melhor uso dessa tecnologia em seus trabalhos acadêmicos ou profissionais futuros, mas para conscientizá-los acerca das limitações dessa tecnologia, possibilitando que eles orientem melhor seus clientes e a comunidade acadêmica em geral. Nessa direção, uma proposta muito breve de como formar tradutores no âmbito das tecnologias de tradução automática pode ser encontrada no livro Tecnologias da Tradução: teoria, prática e ensino, escrito por mim e outra autora (ESQUEDA; STUPIELLO, 2019). Os trabalhos de Gaspari (2001), Garcia (2011), O'Brien (2002, 2010, 2014) e Qun e Xiaojun (2015) também contribuem com propostas semelhantes.

Em resumo, certamente usarei o livro de Bowker e Buitrago Ciro para projetar as futuras disciplinas de tecnologias de tradução pelas quais sou responsável no Curso de Bacharelado em Tradução da Universidade Federal de Uberlândia, Minas Gerais. Assim como qualquer docente da área de Tradução, busco continuamente inspirações para aprimorar a competência instrumental de meus alunos, que hoje em dia é bastante orientada pelos impactos tecnológicos como os promovidos pelos sistemas de tradução automática.

\footnotetext{
"Tradução" com "T" maiúsculo refere-se à tradução como campo disciplinar. Quando utilizada em letra minúscula, "tradução" refere-se ao processo de reexpressão de textos de uma língua A para uma língua B.
} 


\section{REFERÊNCIAS}

BOWKER, L.; BUITRAGO CIRO, J. Machine translation and global research: towards improved machine translation literacy in the Scholarly Community. United Kingdom: Emerald Publishing Limited, 2019.

ESQUEDA, M. D.; STUPIELLO, E. N. A. Tecnologias da tradução: teoria, prática e ensino. São José do Rio Preto: Ed. Transitiva, 2019.

GARCIA, I. Translating by post-editing: is it the way forward? Machine Translation, Dordrecht, n.25, p.217-237, 2011.

GASPARI, F. Teaching machine translation to trainee translators: a survey of their knowledge and opinions. In: FORCADA, M. L.; PÉREZ-ORTIZ, F.; LEWIS, D. R. (ed.). WORKSHOP TEACHING MACHINE TRANSLATION, 8., 2001, Santiago de Compostela. Proceedings [...]. Santiago de Compostela: [s.n.], 2001. p.35-44.

HUTCHINS, W. J.; SOMERS, H. L. An introduction to machine translation. London: Academic Press, 1992.

O'BRIEN, S. Teaching post-editing: a proposal for course content. In: EAMT WORKSHOP TEACHING MACHINE TRANSLATION, 6., 2002, Manchester. Proceedings [...]. Manchester: EAMT, 2002, p.99-106. Disponível em: https://www. researchgate.net/publication/228787033_Teaching_Postiting_A_Proposal_for_Course Content'. Acesso em: 27 jan. 2020.

O'BRIEN, S. Introduction to post-editing: who, what, how and where to next. [S.l.]: Association for Machine Translation in the Americas AMTA, 2010.

O'BRIEN, S. et al. (ed.). Post-editing of machine translation: processes and applications. Cambridge: Cambridge Scholars Publishing, 2014.

QUN, L.; XIAOJUN, Z. Machine translation: general. In: SIN-WAI, C. (ed.). The Routledge encyclopedia of translation technology. London: New York: Routledge, 2015. p.105-119.

Recebido em 19 de fevereiro de 2020

Aprovado em 2 de julho de 2020 